\title{
Finding Meaning in Intermedial Gaps
}

\author{
Mary Simonson
}

\section{Contents}

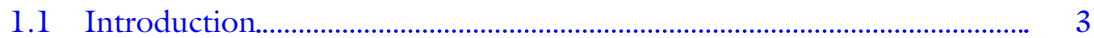

1.2 Ventriloquism with No Voice ............................................................................. 5

1.3 Silent Film with No Image ....................................................................... 12

1.4 Opera with No Song ............................................................................. 15

1.5 Speaking in Another Language .................................................................. 18

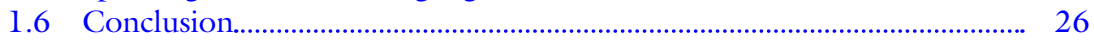

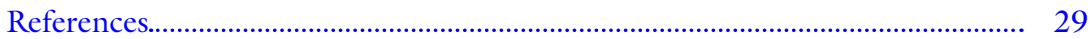

\subsection{INTRODUCTION}

In recent decades, a flurry of excellent scholarship has described media and processes of mediation in increasingly expansive terms. Media, much of this work posits, is not only the specific technologies by which information is disseminated, but also any communicative conduit that conveys ideas or meaning between one place or person and another. As Lars Elleström described in his original "Modalities of media" article and further elucidates in his essay in this volume, for example, media productsphenomenon, objects, bodies, and/or extensions of bodies-transfer "cognitive imports" between the "producer's mind," where they

\footnotetext{
M. Simonson $(\square)$

Colgate University, Hamilton, NY, USA

e-mail: msimonson@colgate.edu
}

(C) The Author(s) 2021

L. Elleström (ed.), Beyond Media Borders, Volume 2, https://doi.org/10.1007/978-3-030-49683-8_1 
originated, consciously or unconsciously, and the "perceiver's mind," where they are received bearing some resemblance to their original state (Elleström 2020: 12-13). Elleström's and other scholarship then elaborate and concretize these models with examples: a dancer develops a concept, generates choreography, and uses their body as a medium of display upon and through which audience members see, hear, and feel some version of that original concept. A photographer sees a scene, decides how to frame and compose it, and captures it on film; the digital photo or print enables viewers to glimpse a version of that original scene. For obvious reasons, these examples almost always involve successful communication: the viewer gets a sense of what is pictured, the photographer deems their captured image acceptable, the audience is able to make sense of the dance, and the choreographer and dancer both feel as if they have shared something with those present.

However, media products - and particularly intermedial products-are not always able to transmit meanings and ideas so smoothly. And at times, media products are envisioned and created precisely so that they will likely not transmit meanings and ideas in a straightforward way. In this essay, I explore a series of historical and contemporary media objects and performances that do not necessarily facilitate a "successful" transfer of meaning, in part because of their intermedial configurations: a silent film about (and featuring repeated performances by) a ventriloquist, another that revolves around about an opera singer's stage debut, radio broadcasts of film programs in the 1920s, and finally, a modern American theater production that relays a narrative through a series of media practices rooted in historical moments, geographies, and languages distant from most audience members' experiences. Each of these media objects and performances mix, combine, and transpose multiple media. In doing so, each conceals as well as reveals: something is lost or obscured in translation. ${ }^{1}$ At times, these "losses" are purely accidental, the result of an overly ambitious agenda: aesthetics and/or content associated with one medium are transposed to another that cannot quite contain them. At other times, these losses are the natural byproduct of experimentation and a still-developing understanding of a medium's modalities, possibilities, and limits: a creator represents a media object in a technical medium of display defined by strikingly different modalities to see how both media will be reimagined, and their relationship to one another reconfigured. At still other times, these losses are entirely purposeful: an aesthetic, social, or cultural intervention designed to yield specific effects. Yet in all cases, these acts of concealment are-or become-meaningful and productive. 
That a media product is likely better suited to one technical medium of display than another is hardly a novel concept. Nor is it news that some media products are more easily representable in certain media, nor that media require contextual frameworks and experiences. Indeed, as Elleström notes in his original "Modalities of media" essay, while technical media are generally able to mediate a range of different media, a television show will more "completely" and "successfully" mediate a film than a painting could, because its modal capacities are far more like those of film (Elleström 2010: 31). In this essay, I am interested in expanding our understanding of what constitutes "successful" mediation, particularly in the context of intermediality. Numerous scholars have argued that intermediality is defined in part by its resistance to completeness and unity. Irina Rajewsky, for example, describes intermedial references as "as-if" situations: though one medium is treated as if it is another, it never actually becomes another. While that medium may "generate an illusion of another medium's specific practice," there remains an "intermedial gap" between the attempted enactment or reproduction of the medium and the medium itself (Rajewsky 2005: 55). These gaps and "as ifs" are often made readily visible; indeed, as Peter Boenisch writes, the broadcasting of these "detours, inconsistencies, and contradictions" refuses our easy immersion into a narrative or world and instead draws our attention to the (inter)media at work (Boenisch 2006: 115). ${ }^{2}$ By creating space for and highlighting these gaps - these moments that withhold as much as they communicate, and that communicate withholding - artists and performers generate a wealth of new expressive possibilities. These new modes of expression, in turn, promise new affective and perceptual experiences for performers and audiences alike. And at times, the creation of moments in which media do not or are not able to communicate smoothly also prompts new aesthetic and technical innovations, reshaping genres and media, and drawing attention in our cultural imagination to media's plasticity and possibility.

\subsection{Ventriloquism with No Voice}

The Unholy Three, a 1925 silent film directed by Tod Browning, is a suspenseful thriller about an elaborate criminal ruse hatched by a former sideshow ventriloquist, Prof. Echo (Lon Chaney), and two of his colleagues, a little person named Tweedledee (Harry Earles) and a strongman named Hercules (Victor McLaglen). ${ }^{3}$ Using his vocal mimicry skills and a clever costume, Echo disguises himself as Mrs. O'Grady, the proprietress of a pet shop specializing in talking parrots, and the elderly grandmother of his 
pickpocket girlfriend, Rosie O'Grady (Mae Busch). “Mrs. O'Grady” uses ventriloquism to convince wealthy customers that the birds in her shop can speak on command. The sales are part of a larger ruse, though. When customers call to complain that their new pets will not talk, Mrs. O'Grady makes house calls; while she convinces the customers that the birds can actually speak, her accomplice Tweedledee, disguised as a napping baby in a pram, is left alone to case the house so the trio can later return and rob it.

The conundrum bound up in depicting this narrative on the silent screen is immediately obvious. Ventriloquism is predicated on aural illusion. The ventriloquist speaks with no movement or other visible sign, throwing their voice in order to vocally animate that which does not speak. Without audible voices, there is no magic: the ventriloquist need not speak with still lips at all, much less throw their voice or disguise their vocal timbre and speech patterns. How to depict ventriloquism and vocal impersonation in the absence of precisely the modalities that define them? Or, to borrow from Kate Newell's essay in this volume, how to "reframe" ventriloquism to be seen and heard as it moves from stage to the silent screen? (Newell 2020). Previews for the film puzzled over the question. As a writer for Picture-Play Magazine wrote, "when the parrots in his shop can't talk Chaney is supposed to imitate them with his ventriloquial talents, and they are probably having a monkey-and-parrot time of it trying to register this on the screen" (Hollywood Highlights 1925: 114).

The film's creators employed a variety of narrative, dialogic, and visual cues to represent ventriloquism and vocal disguise. From its opening moments, the film establishes Echo's identity as a ventriloquist: we meet him performing with a dummy at a sideshow. Though he quickly begins ventriloquizing birds instead, the dummy remains a conspicuous prop throughout the film, constantly reminding us of his skill. Additionally, the film deploys physical markers and intertitle dialects to visually convey Echo's ability to successfully alter his voice. When disguised as Mrs. O'Grady, Echo's bent posture, relatively still lips, gently tilted head, and relaxed cheeks and chin suggest a quiet, gentle voice; her dialogue that appears in intertitles is correspondingly mannered and mild. When Echo breaks his Mrs. O'Grady character or appears out of disguise, however, his face becomes far more animated, his eyebrows raising and lowering for emphasis as his speech emanates from the corner of his slightly distorted mouth. These physical hints are registered in the intertitle dialogue with coarser expressions, slang, and contractions. Frustrated at Rosie's flirting with the naïve and besotted pet store clerk, Hector (Matt Moore), for 
example, Echo rips off his Mrs. O'Grady wig, juts his head forward, and wags his finger in her face, disgustedly exclaiming via an intertitle, "You're makin' a play for that guy!" The film also draws our attention to the sound of voices through offhanded diegetic comments. In one of the early pet store scenes, for example, Mrs. O'Grady tries to shoo Rosie away from Hector by remarking on the effect of Rosie's voice on "baby Willie" (Tweedledee in his disguise), who fusses on the floor nearby. "Little Willie darling heard your voice," the older woman tells the younger. "He wants you to take him bye-bye." Neither these explicit references to character's voices, nor the careful visualization of speech through intertitles and facial expression are accidental: both tacitly encourage audiences to imagine the sounds of these different voices.

As the reviewer quoted above predicted, some of the most striking attempts to visualize Echo's ventriloquism utilize the parrots. During the very first scene in the pet store, Hector comments on Mrs. O'Grady's special ability to make the birds talk. When a customer enters and begins looking at the birds, Hector immediately runs to summon Mrs. O'Grady, telling her (via intertitle), "I think you'd better show the parrots. They talk so well for you." As Mrs. O'Grady obliges, the action is interrupted by an intertitle reminding the audience of Echo's ventriloquial proficiencies and likening the parrots to Echo's dummy: "Echo, the ventriloquist, could make wooden dummies talk - now watch the jolly parrots!" The film immediately cuts to a shot of Mrs. O'Grady, surrounded by caged and loose parrots; as each bird "speaks," speech bubbles appear over their heads containing intertitles depicting the bird's words: "Good morning, Aunty!" "Hello Polly!" "Pretty Lady!" (see Fig. 1.1). The shot cuts to Hector, who again draws attention to Mrs. O'Grady's magical ability to make the birds talk when he raves to Rosie, "Isn't it wonderful how the parrots always talk to your Grandma?"

Echo's ventriloquism is a crucial plot device-the mechanism by which the trio's crimes are facilitated. However, it is also central to the film's climactic scene, and its narrative resolution. Increasingly uncomfortable with the trio's activities, Rosie falls in love with Hector. When the trio botches a robbery, Echo frames Hector and then kidnaps Rosie in hopes of reigniting their former passion. But he cannot bear to see Rosie so miserable, and sneaks into Hector's trial in hopes of exonerating him through a final ventriloquism performance. Echo manages to slip Hector a note instructing him to take the stand and silently repeat the Lord's Prayer over and over, moving his lips without actually making a sound. As Hector 


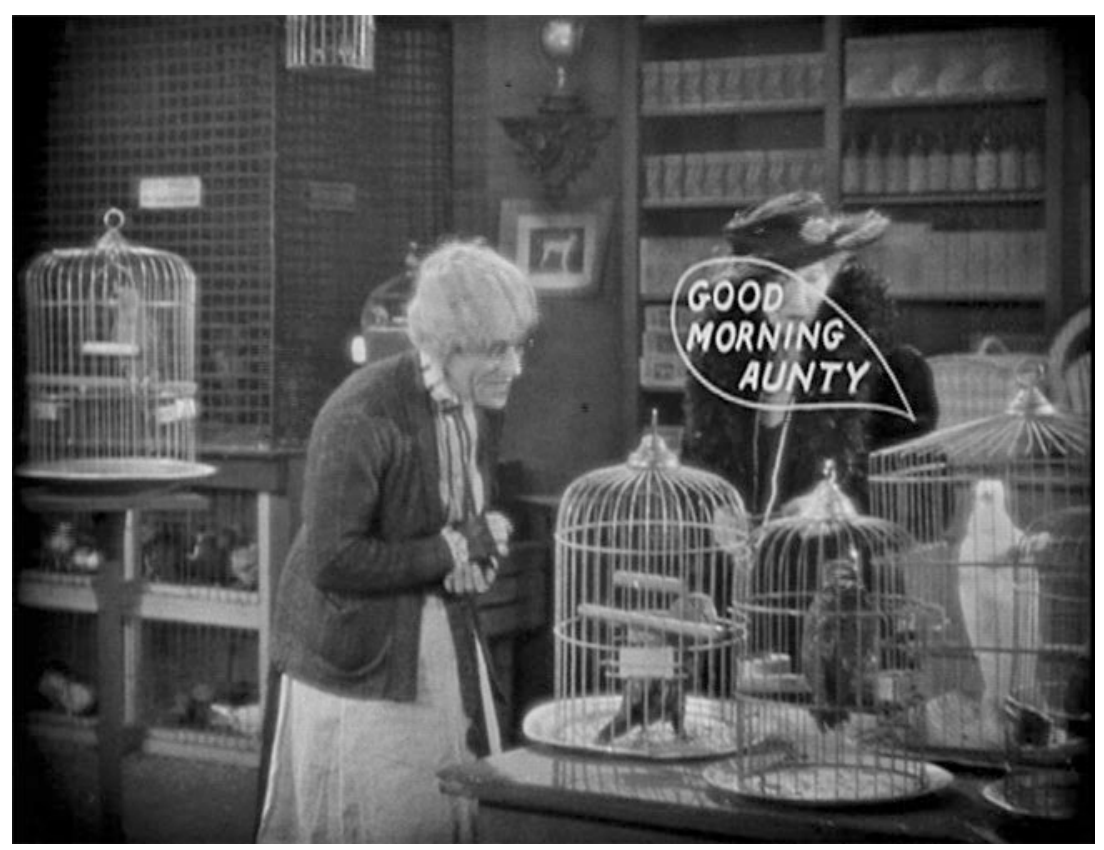

Fig. 1.1 Mrs. O'Grady and her "talking" parrots in The Unholy Three (dir. Tod Browning, 1925). All rights reserved

follows the note's instructions, the film's audience is treated to yet another visual strategy for representing ventriloquism on the silent screen: the camera oscillates between close-ups of Echo in the gallery, his throat and jaw moving slightly as he envoices Hector; first person intertitles exonerating Hector; and shots of Hector obediently moving his lips. Seconds later, Hector draws attention to Echo's ventriloquism when he declares, "That wasn't me talking. I didn't say a word." In this moment, ventriloquism is portrayed by revealing - and commenting on-its mechanics.

While the scene punctures the ventriloquial illusion for the film's audience, the performance goes off without a hitch within the film's diegesis. Neither the judge nor either of the lawyers acknowledge Hector's claim that he has just been envoiced - an act that presumably amounts to perjury. Nor do any of them seem to doubt the contents of his ventriloquized testimony. However, even this diegetically "successful" ventriloquial performance is not enough to clear Hector's name. The judge immediately 
instructs the jury to disregard Hector's testimony on the grounds that there are no witnesses to confirm this new story, and sends them out to deliberate. Narrative closure comes only when Echo intervenes and makes a full confession. In the end, ventriloquism can only get so far on the silent screen.

As was common practice, a talkie remake of The Unholy Three (directed by Jack Conway) was released by MGM in 1930, shortly after the widespread conversion to sound film. The remake retained the silent film's narrative conceit and characters, and both Lon Chaney and Harry Earles reprised their roles alongside an otherwise new cast. It also retained ventriloquism as a drawing card, central plot device, and Echo's defining talent. Advertisements and previews for the new Unholy Three touted the imminent logic of making a sound version of this particular film. A writer for Film Daily noted that the story was "a bigger draw in sound, for so many of the dramatic incidents depend on audible effects, such as the ventriloquist's dummy," and advised exhibitors to highlight Chaney's "varied speaking voices" in their pitches to audiences (The Unholy Three 1930b: 10). With sound, not only could audiences marvel at Chaney's vocal impersonations, they could also hear his voice magically emerge from his dummy's flapping mouth as his own lips remained remarkably still.

However, though sound film includes an aural channel, it is in some ways no more appropriate for the display of ventriloquial acts than silent film: it does not replicate the modalities that define ventriloquism and vocal impersonation, either. Ironically, it is because sound film is itself a ventriloquial medium that it cannot convincingly represent ventriloquism. ${ }^{4}$ Watching sound films, audiences are invited-indeed, compelled-to pretend that the sound they hear issues directly from the image that they see on screen. In reality, though, these synchronized images and sounds are usually the result of careful construction, re-recording, dubbing, and extensive editing. As film sound scholar Michel Chion notes, the materiality of film requires "an incision or cut between body and voice" that is then covered over enabling us "to believe, implicitly or explicitly, that the body and voice cohere in some self-evident, natural way" (Chion 1999 [1982]: 125-126). By 1930, MGM was certainly using such techniques; and thanks in part to decades of cinematic "attractions" that openly displayed all sorts of editing tricks, many audience members attending The Unholy Three were savvy enough to understand that Lon Chaney's 
ventriloquial stunts and vocal disguises could easily have been generated through technical means.

Readily anticipating audience skepticism, MGM staged a publicity stunt to reassure audiences that it was actually Chaney's voice they were hearing, and not a cast of vocal extras dubbed in: Chaney issued a signed affidavit that read, in part, "The ventriloquist's, the old woman's, the dummy's, the parrot's, and the girl's are actual reproductions of my own voice and in no place in said photoplay or in any of the various characters portrayed by me in said photoplay was a 'double' or substitute used for my voice." (Inside stuff-Pictures 1930: 49; The Unholy Three advertisement 1930: 26). The affidavit was widely reported in film trade press, fan magazines, and daily newspapers, and was reproduced in advertisements for the film. Notably, however, the affidavit-and the press surrounding it-blatantly sidesteps larger questions about the film's representations of ventriloquism. The affidavit pointedly does not claim that Chaney's vocal impersonations were synchronously recorded with the film's image track, nor that he ventriloquized his dummy or the parrots live on set. While his vocal impersonation skills were validated, then, little was done to convince audiences of the validity of his ventriloquial performances.

Strikingly, the most convincing display of vocal trickery in the talkie version of The Unholy Three is achieved through failure. One of the few moments in the talkie that significantly departs from the silent version comes in the final courtroom scene. Instead of ventriloquizing Hector from the audience, Echo actually takes the witness stand in his Mrs. O'Grady disguise. As he testifies, his vocal disguise slips: Mrs. O'Grady's voice descends a bit, then a bit more, and eventually is so low that the defense attorney approaches her and rips off her wig, revealing the whole ruse. Unmasked, Echo confesses and is found guilty and sentenced. While the silent version ends with the failure of ventriloquism, the sound version culminates in actual ventriloquial failure. The authenticity of Echo's vocal trickery is confirmed by showcasing its dissolve.

The silent and sound versions of The Unholy Three make a counterintuitive proposition: to represent ventriloquism using a medium-film-that at best obscures and at worst undermines the illusion that defines the art. While these films develop strategies to do so, the fact remains that silent and sound films both lack the modal configuration to "completely" mediate a ventriloquial performance-or, to put it differently, ventriloquism exceeds the modal capacities of the film projector and screen. Despite this modal mismatch, though, the two Unholy Three films are hardly failures. 
Lon Chaney was famed for the range of characters he convincingly embodied: reviewers and fans marveled at his transformation from one film to the next. Playing a ventriloquist offered Chaney the opportunity to embody radically different characters within the same film, and at times, within the same scene. Reviews and commentary on the silent film highlight Chaney's marked visual transformations as he shifted from Echo to Mrs. O'Grady, as well as his expressive abilities within each of the roles (The Shadow Stage 1925; The Unholy Three 1925a: 45; The Unholy Three 1925b: 845). Describing the film's final moments, a writer for Exhibitor's Trade Review noted that though Echo lightly bid Rosie goodbye "with a laugh that is akin to mockery" after his confession, within seconds of her departure, "his seamed face is limned with the searing lines of heartbreak" (The Unholy Three 1925a: 45). Similarly, the sound version enabled audiences to hear Chaney's voice for the first time and treated them to Chaney's vocal impersonation abilities. Long nicknamed "the man of one thousand faces," the sound version of The Unholy Three led the press to embrace a new moniker: "the man of one thousand voices" (Nelson 1930: 32; Moak 1930: 44). While Chaney's transformations had in the past hinged on costumes, makeup, and his acting abilities, The Unboly Three films first implied and then revealed that his disguises and transformations were audible, as well: he could fake convincing laughter, shift his vocal timbre, and alter his speech patterns. Here, Chaney dazzled with his ability to shift in a moment from one emotion to the next, one voice to another, one person to a different person.

Shoehorned into the film's narrative, ventriloquism also prompted innovation within the cinematic medium and the film industry more broadly. The creators of the silent Unholy Three explored how the cinematic medium might visualize vocal production and illusion, as well as the acts of hearing and mishearing; in doing so, they reconfigured and reimagined silent cinema's sensorial modalities. Some of the strategies used to represent ventriloquism-intertitles, moving lips and expressive faces, close-ups and short/reverse shot sequences—align with silent film's usual techniques for conveying speech. Other strategies might themselves be considered ventriloquial: speech bubble text and oscillating throats speak "for" and replace these time-tested techniques. ${ }^{5}$ In the sound remake of The Unholy Three, too, Chaney's ventriloquist character prompted the film's creators, MGM, and even the press to negotiate and consider how best to acknowledge and address audience awareness of sound cinema's mechanical and technical underpinnings-precisely in order to enable 
audiences to suspend their disbelief or even disavow film's status as a highly constructed medium. The intermediality of both the silent and sound versions of The Unholy Three, then, generates successful medial experimentation, recombinations, and fluidity, beginning to reimagine, challenge, and construct the defining modalities and medial limits of silent and sound film.

\subsection{Silent Film with No Image}

In the first years of the 1920s, radio, which had been limited to military use during World War I, emerged as a highly popular and much debated technology. Amateur radio operators and new commercial radio experiments flooded the airwaves, broadcasting a range of different program formats, content, and musical styles. Among those who embraced and helped to shape the emergent medium were film studios and exhibitors: radio was viewed as an ideal venue for advertising new pictures, a sort of live fan magazine by which movie stars could directly address their adoring audiences, and a potential source for film accompaniment-if not a means of making films "talk."

While many in the industry eagerly explored radio's possible applications, Samuel "Roxy" Rothafel, then the manager of the Capitol Theater in New York City, was particularly visionary. In 1922, he began broadcasting concerts by the Capitol Theater orchestra over WEAF, and hosting shows that promoted the theater's film programs and featured performances by a rotating cast of orchestra members and the other performers who appeared in theater presentations before and between films. By April of 1923, Roxy's radio broadcasts were synchronized with his evening theater program - or rather, as media scholar Ross Melnick has argued, the Capitol's evening theater program was dictated by the broadcast schedule (Melnick 2012: 212). ${ }^{6}$ Period articles in Radio Digest and other trade publications reported that at 7:20 pm, Roxy would introduce the evening's broadcast from near the Capitol Theater's stage (but out of ear- and eye-shot of the audience in the theater), sharing details about the orchestra's musical selections and other things they would hear in the two hours ahead (Lanzius 1923: 5). Then, at 7:30 pm, the radio audience would be invited to listen along with the theater audience to the orchestral overture that traditionally opened silent film presentations in movie palaces. But radio listeners were not just allowed to listen in on the theater's musical performances. As the newsreel and other short films appeared on the 
Capitol's screen following the overture, the radio audience heard Roxy's careful descriptions of each film's narrative and visual imagery over the accompanying music. Then, as live performers appeared on the theater's stage between the short subjects and the evening's feature, Roxy introduced each and, when necessary, described precisely what the theater's audience was seeing, offering audiences mental images to compliment the musical performances and other acts that they heard through the ether. Shortly after 8:00 pm, as the feature film began, Roxy and his "Gang" of performers moved to the theater's broadcasting studio and continued their broadcast with further conversation and additional musical performances until 9:00 pm.

At first glance, these radio broadcasts, and particularly the segments broadcasted live from the theater's stage, seem as counterintuitive as a silent film about ventriloquism. Here too, media objects-silent films and live stage performances-were being mediated by a technical medium of display-radio-with significantly different modal characteristics. It is tempting to read these broadcasts as a case of remediation gone wrong: the nascent radio industry's attempt to take up and incorporate the "older" medium of silent film in order to draw legitimacy from and ultimately displace it. ${ }^{7}$ And certainly, the broadcasts followed the remedial logic of claiming (and benefiting from) the status of silent film and the artists who work in it, much as silent film did with opera, as is discussed in the next section (Bolter and Grusin 1999: 69). Broadcasts of silent film presentations borrowed and represented silent film's familiar entertainment formats, compelling ready-made narratives, and well-prepared musical and stage performances. They also attempted to invoke, if not create, the atmosphere of the silent film theater in listeners' living rooms. As Radio Digest writer Evelyn Lanzius reported in 1923, “One evening recently, previous to the rendering of 'Love's Old Sweet Song' by 'Betsy,' Mr. Rothafel requested his Radio audience to lower their lights, thus bringing his own lighting effects into their homes. Many wrote in to say that they had followed this suggestion with telling effect" (Lanzius 1923: 5).

Even as these radio broadcasts remediated silent film, they also distinguished themselves from it. On air, Roxy sought to create an intimacy that was impossible at film screenings in his enormous Capitol Theater. His patter was familiar, his descriptions accessible and casual. He presented himself as a personal friend of his listeners, and encouraged the musicians and performers who joined him in the studio to do the same. He regularly introduced and referred to his musical guests by first names and 
nicknames: conductor William Axt was called Billy on air, singer Betsy Ayres was simply Betsy, and violinist and concertmaster Eugene Ormandy was often presented as "The Blue Blonde." The featured performers chatted casually with the listening public, generating both public personae and imagined relationships that were nearly impossible in a darkened film theater. As Lanzius wrote in Radio Digest, "Roxie [sic] introduces each artist most informally, and encourages them to talk in little personalities to the invisible audience, these being mostly in humorous vein, and there is no doubt that there is an unusual sympathy and bond of interest between the artists of the Capitol broadcasting studio and the Radio listeners" (Lanzius 1923: 5). While radio lacked the visual dimension so central to silent film and the live performances presented alongside, its modalities and the social and cultural practices that surrounded it enabled radio to exceed silent film in meaningful ways.

It is important to remember, however, that Rothafel's broadcasts were driven as much by Rothafel himself-a fixture within silent film exhibition-as they were by those in the radio industry. Even if those at WEAF and its parent company hoped that the venture might legitimize and allow radio to compete within the entertainment landscape, and some within the film industry engaged in a fair amount of hand-wringing over radio's potential to decrease filmgoing, Rothafel and other exhibitors who broadcast from their theaters clearly thought of the practice as a means of renewing and expanding silent film's cultural relevance. Period audiences, too, seem to have understood that listening to silent film via radio was profoundly different than attending a film presentation at the theater; that is, the technical medium of display profoundly changed the media product (Elleström 2020: 33-40). Indeed, audiences in the 1920s likely used the broadcasts as a means to imagine the original media objects and performances. ${ }^{8}$

Rothafel's broadcasts hardly shied away from radio's inability to display the very images that constituted the film-this intermedial gap. Instead, they highlighted the gap by describing the images cast onscreen in great detail. As he narrated the film shorts and stage action, Rothafel was telling audiences exactly what they were missing, exactly how their experience differed from that of the audiences in his theater, exactly what they were being denied by their radio. As Evelyn Lanzius reported, Rothafel was well aware that film's "chief form of entertainment, the picture, cannot be transmitted through the air-yet-and if people who hear the Radio concert like them in Radio form they must actually attend the theater to get 
the picture and their interest is greatly stimulated by the Radio presentation" (Lanzius 1923: 5). Nor was it only the film images that were leveraged to help audiences visualize the show, and to draw them into the theater. After audiences began writing to the Capitol asking for photos of "Roxy and his Gang," postcards featuring portraits of various performers in the broadcast studio were produced and mailed to fans; by June of 1923 , it was reported that thousands of requests were in the process of being filled (Lanzius 1923: 5). Similarly, magazine writers were invited to visit the studio during broadcasts, resulting in articles that Melnick argues offered fans yet another "visually corollary to the disembodied voices audiences had grown accustomed to" (Melnick 2012: 219). I would go a step further: the postcard portraits and colorful descriptions that the writers penned following their visits displayed the broadcasts in other mediaphotographs and magazine articles-with yet other sets of modalities to compliment the radio broadcast's intimate aural characteristics. Together, these media enabled audiences to better imagine the sights, smells, feel, and energy that accompanied the voices they heard over the air. This intermedial "migration" of stage and screen performance to radio, then, not only bolstered the stage and screen performances themselves, but also prompted additional intermedial layers and movement. The resultant intermedial web of still and moving images, print journalism and fan letters, bodies on stage, and voices over the air traversed and defined not only media but time and space as well.

\subsection{Opera With No Song}

In the fall of 1920, Universal released the silent film Once to Every Woman, directed by Allen Holubar and starring Dorothy Phillips as Aurora Meredith, a blacksmith's daughter who also happens to possess a beautiful singing voice. ${ }^{9}$ The film joined a host of other silent films that showcased opera. While many of these films adapted operatic narratives for the screen-there were silent versions of Bizet's Carmen, Mascagni's Cavalleria Rusticana, and a host of others-others actually wove opera into the plot. ${ }^{10}$ Once to Every Woman is lost, but period reviews and advertisements for the film and its presentation at various theaters make clear that Holubar's production did both. Early in the film, a wealthy patron discovers Aurora singing in her village church's choir and sends her to Europe for training, where she makes a successful operatic debut. Eventually, Aurora returns to the U.S. to appear as Marguerite in Charles 
Gounod's opera Faust, and in hopes of distancing herself from an unwanted Italian admirer. As Aurora appears onstage in the opera (in the film), however, it is revealed that her Italian admirer has also crossed the Atlantic, and is seated in the theater's balcony with a gun. As she sings, he shoots her and then kills himself, interrupting the opera and Aurora's American debut, and throwing the theater into chaos. Eventually, Aurora recovers physically, but the trauma of the violence leaves her unable to sing. Deserted by her European friends and fans, her career all but over, she returns to her parents' home alone. Even here, she finds no solace: her mother becomes ill and dies shortly after her homecoming. In a melodramatic twist, however, this second trauma restores her singing voice: in her mourning, Aurora begins to sing again.

Numerous scholars have theorized the popularity of filmic adaptations of opera in the silent era: opera plots were familiar, compelling, and easily adaptable to the screen, and opera carried the sort of artistic value and cultural prestige that the early film industry sought. Moreover, operatic adaptations relieved theater musicians and music directors of the timeconsuming work of composing a musical score or compiling cue sheets from an endless selection of existing music. Instead, they could cobble together instrumental versions of familiar arias, choruses, and incidental music from a single opera score. For audience members familiar with the adapted operas, the resultant medleys were enjoyable, even when rendered solely by theater pianists, organists, or instrumental ensembles. Yet these sorts of films-particularly those like Once to Every Woman, which actually showcased opera singer characters and their performances-presented a fascinating challenge, too. How to represent opera singing without audible voices? Like the Lon Chaney's silent and sound screen ventriloquism and Roxy's Capitol Theater broadcasts, Once to Every Woman offered audiences a representation of one medium in another medium that lacked the necessary modal qualities.

Exhibitors were clearly sensitive to this modal dissonance, and some developed strategies to remedy it, including the introduction of live performers into the film's presentations. When Once to Every Woman was screened at the Stratford Theater in Chicago in December of 1920, for example, the film projection was paused during the scene in which Aurora appears onstage as Marguerite, and a soprano dressed in a costume modeled on Aurora's stepped into the spotlight on the Stratford stage in front of the screen and sang Marguerite's "Jewel Song" from Faust. As she concluded, the film projection resumed and the soprano disappeared into 
the darkness. One film trade journal reported that the effect was seamless: "the impression conveyed to the audience was that Miss Phillips had stepped out of the screen to sing the aria" (Chicago Theatre's presentation elaborate 1921: 367). It was also undoubtedly dramatic: while the filmic medium could offer audiences Aurora's beautiful voice only as a mythical, unheard object, the soprano's appearance onstage transformed the silenced into the sounding, the mythic into the realized.

The Stratford staff developed an equally compelling strategy for restoring Aurora's voice in the theater when her mother's death restores it onscreen. As Aurora opens her mouth to express her grief in the film, the soprano, hidden offstage, began singing the popular nineteenth-century song "Ben Bolt," which remembers a woman who is now buried in a church cemetery. Once again, the mythical voice became manifest: that which audiences believed to be unavailable first due to the modalities of the silent film, and then due to the film's narrative, became audible. Additionally, this (re-)envoicing of Aurora aligned the film's story and its presentation: those in the theater experienced precisely the vocal loss and return that was depicted onscreen. ${ }^{11}$

For film audiences today, who rarely experience films accompanied by live musicians or bookended with stage performances, these interludes might seem like temporal and medial interruptions. However, the review quoted above suggests that audiences in 1921 probably did not perceive these moments as ruptures at all. Rather, the soprano's first performances were understood as part and parcel of the film's presentation-indeed, as part and parcel of the film itself. Or, to apply Andy Lavender's notion of performer as medium from this volume, the soprano, "herself a complex technical medium," operates within the larger media product of the silent film (Lavender 2020: 117). Once to Every Woman's intermedial play with opera was, like the examples above, an "as-if" situation. Though momentarily masquerading as opera, the silent film never actually became opera; in fact, even experiencing it "as" opera required audiences to engage in a significant suspension of disbelief. Yet together with Stratford Theater staff and performers, those audience members who were willing to embrace the "as-if" reimagined and remade Once to Every Woman to allow for audible voices. In doing so, they also temporarily reimagined and remade the technical medium of display of silent film, enlarging the audience's conception of its modal boundaries and qualities to more fully accommodate the media product. 


\subsection{Speaking in Another Language}

In the historical examples discussed above, media producers developed compelling reasons and strategies to represent or mediate performances using technical media of display that would inevitably withhold, remove, truncate, and radically reconfigure those performances. My final example is a bit different. Club Diamond is a theater piece in which creators Saori Tsukada and Nikki Appino (with composer Tim Fain) consciously incorporate-indeed, thematize - the sort of medial withholding, truncation, gaps, and "as ifs" that the historical examples stumble into. A deeply complex work, Club Diamond uses intermedial layers and combinations to purposefully "other" the audience, confronting them with the unfamiliar (and at times, that which seems unintelligible) narratively, medially, and structurally. By doing so, the work invites audience members to explore the affective experience of its protagonist(s), calling upon them to traverse gaps, piece things together, and compensate, just as the work's protagonist(s) must.

The piece opens unassumingly. Tsukada stands center stage dressed in modern clothes, a large film screen behind her and a podium and clothes rack to her left, and cues the lights and an audio recorded monologue. Almost immediately, identities begin to blur. Is the first-person monologue about a childhood love of Disney and drawing Tsukada's autobiography or that of a character she is embodying - and why is it recorded? Tim Fain enters with his violin, only deepening the uncertainty: is he accompanist or character? Is this prologue or performance? As the recorded monologue ends, the pleasant haze seems to clear, momentarily: Fain begins tuning and Tsukada puts on a costume, declaring, "My friend Tim and I are going to tell you a story about how I came to the United States." Within seconds, though, her voice echoes as the recorded monologue resumes, reintroducing her, or rather, reintroducing her in her newly costumed role: that of a prominent Japanese silent film narrator, or benshi, in 1927. ${ }^{12}$ Tsukada-as-benshi takes her place behind the podium as the film screen flickers alive and Fain begins to accompany the images on screen, but again, the performers and their roles are quickly complicated. Fain lowers his violin mid-phrase, revealing that he is playing (is he playing?) over and with prerecorded layers of music, and onscreen, the film's title appears: it too is called Club Diamond, and it too credits Nikki Appino as director (in the theater production, she is credited as a creator), Saori Tsukada as the principal performer (here, she is credited as "Heroine," 
"New Girl," and "Bartender," while in the theater production program identifies her as "performer" and creator), and Tim Fain as composer, along with a fleet of others. ${ }^{13}$ Is the screen simply a mirror of the stage, or has Club Diamond migrated from one medium to another? (See Fig. 1.2.)

As the film begins to roll, it is immediately revealed that it is neither. Onstage, Tsukada-as-benshi describes the film images as they flash, drawing attention to particular elements, providing sound effects to deepen moods and clarify actions, and offering extensive commentary on the various characters and their activities - including, of course, those of Tsukadaas-Heroine and her other screen roles. Yet he does so almost exclusively in Japanese, despite the fact that the work premiered in New York City for a predominantly English-speaking language, and has thus far been performed for audiences mainly of English speakers. Recognizable place names and English expressions occasionally creep into the benshi's narration, but Japanese dominates, forcing audiences into a space of disorientation, even incomprehension. English-speaking audience members must draw clues from the images onscreen, the context in which the benshi

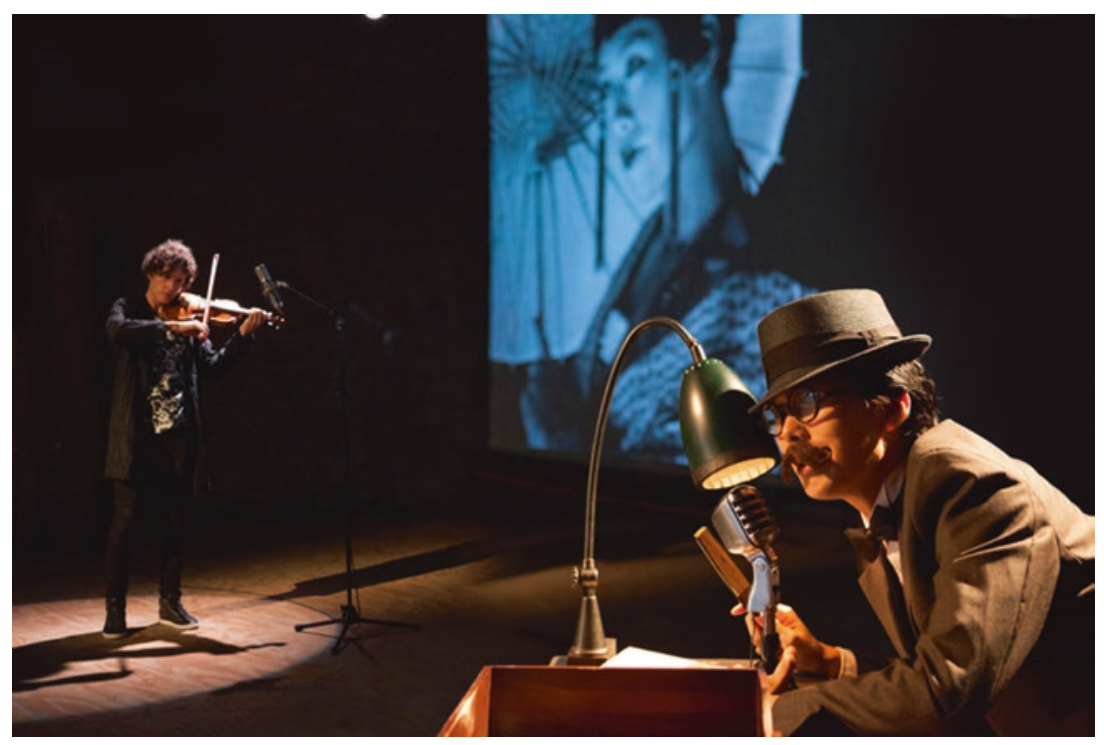

Fig. 1.2 Benshi (Saori Tsukada) and Musician (Tim Fain) in Club Diamond. (Photo by Kathryn Raines, courtesy of Nikki Appino and Saori Tsukada) 
speaks, and his expressive face and gestures. As he dramatizes the images that flash on the screen in front of us, the benshi (to borrow from Andrea Virginás 2020: 152-159) dramatizes and prolongs the act of perceiving and interpreting the film, guiding audience reactions before they fully understand what they are seeing. ${ }^{14}$

Shot in black and white, the film's palette, pace, and aesthetics convincingly pass as a 1920s production. The film includes the sort of experimental elements, visual trickery, and cinematic "attractions" common in silent cinema. Structured in ten chapters, the film opens in Japan, where the Heroine is working as a film actress. Almost immediately, she is rejected in favor of a nearly identical replacement. Gutted, she is crying on a bench when a small bird - a symbol of opportunity in Japanese culture, an intertitle teaches us, and a recurrent symbol in the piece-lands near her, inspiring her to strike out for a new life in the Hollywood. After a long boat journey filled with flashbacks to the Heroine's rejection, she arrives in New York City. A series of montages, shadowy shots, and rapid cuts suggest the disorientation of the newly arrived immigrant: the Heroine's purse is stolen and the police pay her no mind, the streets and subway become a maze, crowds push and jostle. Through a series of intertitles, New Yorkers instruct and reprimand her: "What do you want, lady?"; "I DON'T SPEAK CHINESE!"; "Come on, just get on the bus!" The English titles do little to quell the anxious, overwhelming mood created by the film's quick cuts, its fast, noisy musical accompaniment, and the benshi's rapid, audible breaths and quavering, high-pitched stuttering as he inhabits the Heroine. As the narrative unfolds, one wonders: is this a version of Tsukada's own coming-to-America story, the story she promised to tell? Is Tsukada-as-Heroine an avatar for Tsukada herself? Or is such an assumption both impatient and essentialist?

By Chapter Five, the Heroine has found her way to a hotel, but it offers neither relief nor a sense of safety. It is dark and as she traverses the hallway, hand-drawn spider webs appear along the walls. She cries herself to sleep and awakens to the sound of the bird's wings as it alights atop a copy of Variety, where she finds a wanted ad seeking "Oriental Girls" to work at Club Diamond. At the club, she is met by Tsukada-as-Bartender, bossa nova-inspired music, and a male boss who takes advantage of her in her dressing room between performances. The film quickly turns nightmarish: the benshi's narration becomes increasingly frantic and Fain's ascending melodies become louder and stormier as our Heroine dreams a montage of images and moments: her boss's cigar, his hand on her leg, toasting 
glasses, the doorway to her hotel, static and glitches, large black birds, dancing parasols, more glitches, then a black screen. "Chapter Nine: Revolution" flashes onscreen, but the film immediately begins to decay, frames and sprocketed edges rushing past and a film leader's countdown numbers obscuring shots of the Heroine before the image disappears completely and projection ceases. The final chapter promised in the film's opening titles is excised: any semblance of a storyline explodes, as does the silent film industry and the benshi's cultural status and career, as "talking films" revolutionize the global entertainment scene. Just as the recorded monologue that began the work was punctured by Tsukada's declaration that she and Fain would tell us a story, and this statement was punctured by Tsukada's sudden transformation into the benshi character, now the benshi's performance and the medium of silent film are dramatically interrupted, leaving a bewildering, gaping fissure.

As Tsukada-as-Heroine vanishes from view, Tsukada's recorded monologue resumes. The last time the audience heard this voice, it was introducing the benshi to us. Here, it continues narrating his story, describing the death of a career and lifelong love: "You want to ride it out. You try to ride it out. But suddenly, you become [...] ancient." Tsukada-as-benshi removes his stage outfit slowly, inhabiting the rhetorical "you" of the monologue more fully with each movement. But the monologue pivots, and Tsukada's voice describes the desperation that drove her to answer a newspaper ad titled "looking for girls," recounting an experience working as an escort that parallels Tsukada-as-Heroine's and further collapses the two characters into one, despite the century gap.

Meanwhile, in the corner of the stage, Tsukada has transformed from benshi into kamishibaiya, a type of itinerant street performer taken up by many benshi after the introduction of talkies, who entertained children with candy and paper plays in postwar occupied Japan. ${ }^{15}$ In white coveralls, a hat, and goggles, Tsukada-as-kamishibaiya mounts a bicycle with a large wooden box (butai) on the back, and rides unsteadily to center stage, radio blaring. He parks and sets his stage, opening the butai to reveal a candy display and a set of illustrated storyboards displayed in a frame, and then begins his performance. An informal street act from the back of a bicycle for Japanese and American expat children, the kamishibaiya's performance lacks the polish and ceremony of the benshi's. Yet the audience is encouraged to understand the ragtag street performer as the benshi reinvented. Tsukada-as-kamishibaiya retells the same story that Tsukada-asbenshi did earlier, narrating the heartbroken Japanese film star's trip to 
New York, her frantic navigation of the unfamiliar city, and the rundown hotel and club where she finds herself living and working. Though the kamishibaiya uses a few more English words and phrases than he had as benshi, the narration remains largely in Japanese, and is performed with the same dreaminess and deep emotional investment. Even the images featured on the storyboards harken back to the silent film: several are exact replicas of illustrations from the film. This mirroring of kamishibaiya and benshi hints at the continuity of another pair that, though separated by time, are increasingly difficult to tease apart: our film heroine and the Tsukada character who emerges in the recorded monologue.

The paper play ends as abruptly, and as traumatically, as the film-and at exactly the same point in the narrative. The Heroine's work at the club is introduced with a bright red card with swoops of yellow that resemble stage curtains and the same bossa nova tune that accompanied the club scenes in the film, and suddenly, the kamishibaiya abandons his narration to move about the stage, stomping his feet and beating a shaker against his palm percussively. As narrator becomes musician, musician becomes dancer: Fain moves increasingly extravagantly to his own violin music and the kamishibaiya's rhythms. It is a musical duet and pas de deux in one, the violinist seemingly drawn into the kamishibaiya's postwar Japanese world, into his paper play, into Club Diamond. The musician and kamishibaiya whirl in synchronization, crouching and then unfurling their bodies to stand upright only to bend again, more quickly, more frantically, as the music grows increasingly disjoined and then suddenly, stops. The two pull apart and the kamishibaiya resumes his narration, quiet and still. Then, a flourish: he tosses a handful of confetti and, as Fain begins a pentatonic pizzicato passage, removes the red storyboard to reveal a green card covered with white confetti. Instead of quickly hiding the previous board, though, he gracefully flips it overhead, revealing a muted image of the rising sun flag before depositing the board behind the others. It is a fleeting but potent symbol that hints at the kamishibaiya's worldview and orients the entire scene in time and space, differentiating this telling of the Club Diamond tale from the earlier silent film. Tension grows as the kamishibaiya continues on, mimicking the heroine's panicked high voice and beating a drum attached to his bicycle with increasing power until he bends from the waist, gasping and crying - an embodied rendition of the heroine's bad dream. He straightens, covers the storyboards, and abruptly dismisses the crowd: "The end. Everybody go home." 
Unexpectedly, though, the kamishibaiya does not exit. Instead, accompanied by a haunting ascending violin melody, he wheels his bicycle to the right side of the darkened stage, where he pulls open the reverse side of the butai to reveal a built-in film projector. Squatting next to it, he extends the projector's lens forward, flips on the lamp, and begins rotating the bicycle's pedals to power the projector. An intertitle identical to those in the Club Diamond silent film flashes onscreen, introducing the final, unseen segment of the film: "Chapter Ten." A Universal Studios International News Reel titled "Oriental Cutie makes it big in Hollywood!" begins to roll, presenting Tsukada-as-Heroine blowing kisses to her adoring fans. The newsreel is a talkie, with a jaunty orchestral march accompanying the opening action and then voiceover narration regaling us with tales of this "new born" film star: the final chapter has finally arrived, and it has arrived in sound. The film captures a final shot of Tsukada-asHeroine outdoors, dressed in white; the camera lingers on her face, and then a "The End" title flashes onscreen, with a subtitle added a few seconds later: "Made in the USA." Tsukada-as-kamishibaiya slows the bike pedals as the image flickers out. He rises, removes his goggles and hat; suddenly, it is Tsukada who stands before us blinking, then licks her lips and begins a live monologue about the drawings that she would make and fax to her parents in Japan to show them her new New York life, and her father's advice that she keep talking, even imperfectly, because Americans do not like silence. Delivered quietly and haltingly, the monologue stitches together the childhood reminiscences from the first recorded monologue, her fraught adjustment to New York City detailed in the second recorded monologue, the kamishibai drawings, the fate of the benshi in our culture of sound and talk, and the linguistic and social gulfs between Japanese and U.S. culture that the benshi, Tsukada-as-Heroine, the kamishibaiya entertaining postwar children, and Tsukada herself all face. In this final, subdued moment, Tsukada's various characters collapse into one another even more profoundly, across time and space, gender and career, identity. Onstage, Tsukada points upward, cueing the lights.

Brilliantly coherent as it moves from stage to screen to paper play and back, Club Diamond nonetheless generates the same sorts of medial and narrative gaps, fissures, and disorientation as my earlier examples. In addition to the overlapping, intertwined characters that lead audiences to constantly question who is speaking, for whom, and whose stories we are witnessing, Club Diamond positions English-speaking audiences as linguistic "others," thematizing the disorientation and partial understanding 
so familiar to immigrants and travelers. ${ }^{16}$ Creating the piece, Appino and Tsukada meticulously constructed the benshi and kamishibaiya's speeches such that one word, perfectly hit, might carry an entire paragraph, and generated visual cues to highlight the importance of visuality and looking when navigating linguistically inaccessible spaces. Nonetheless, these sections withhold as much as they reveal, prompting viewers to constantly question what and whether they understand, and to settle uneasily into a space of not quite knowing.

For most audience members, the figures of the benshi and kamishibaiya are as unfamiliar as the language of their narration. Indeed, the benshi tradition itself is a uniquely Japanese practice of which relatively few Americans are aware, and even fewer are familiar. For that matter, though silent film has its enthusiasts, it likely seems quaint and distant to modern audiences. Kamishibai performances are even more mysterious in an American context. Despite the ubiquity of these performers in postwar Japan, the medium has no real American corollary. While the kamishibaiya and benshi may offer historical, geographical, and political clues to some audience members, then, many more are likely to experience them as lacking contextual qualification, to borrow a useful term from Elleström (2020: 60-64): removed from their historical, social, and cultural contexts and represented in a contemporary work of the theater, the benshi and kamishibaiya lose a bit of their intelligibility. Yet the use of contextually unqualified media is precisely what enables Club Diamond to generate gaps in which audience members must flounder, compensate, piece together, and reorient.

The gaps and uncertainty built into Club Diamond come with costs. Linguistic unfamiliarity makes it easy to miss narrative action. Audiences less familiar with twentieth-century politics, media history, and performance practices can easily find misunderstand when or where various sections of the work are set. Important details can slip by without registering, particularly while audience members work to piece other details together in their minds. Even as a music and media scholar who studies silent film and performance, I overlooked a number of compelling moments in my first several interactions with the work-and none of them were particularly nuanced or veiled. In a Skype conversation with me (17 July 2019), Tsukada noted that younger audience members, in particular, seem to miss visual and historical cues, in large part because they do not have the historical framework through which to "read" the work's characters and 
action. As a result, she and Appino continue to consider if and how they should make certain elements-such as the political and cultural context in which the kamishibaiya performs, and the political overtones that make their way into his performance when, for example, he displays the rising sun on the reverse of a storyboard-more legible to audiences who lack the historical understanding to situate him and his actions.

The pleasure - and ultimately the legibility—of Club Diamond depends in large part on the intermedial web it constructs. Tsukada's immigration story is told in a series of live and recorded monologues; a second, slightly abstracted version of that story is told on film and in a paper play. Each time the narrative is cut off, a medial transposition is forced; each medial transposition offers audiences a new set of modalities through which to experience and interpret this story. Tsukada's second monologue, for instance, translates moving images into spoken words, adding precision and detail. Similarly, the simple images of Tsukada-as-kamishibaiya's paper play highlight and distill themes easily lost in the silent film's elaborate moving images or the pace of the monologues. With each medial transposition, too, layers of significance accrue around the work's recurrent symbols, and the audience is resituated in space and time, moving from the 1920 s and 1930s to the late 1940s and 1950s and on to the present, and between Japan and New York.

Club Diamond showcases the continuity and synergies not only of the narratives told within these various forms and genres, but also of the forms and genres themselves. The piece narrates the evolution of silent film into sound film, and more subtly suggests the emergence of kamishibai from the ashes of the silent film industry. By virtue of casting and narrative, the benshi and kamishibaiya are also inseparable from the silent film starlet, the contemporary immigrant actress and Tsukada herself. Moreover, aesthetics and modal qualities associated with one medium are frequently deployed or at least invoked in other media in the piece. With the repeated interruptions and truncation of the narrative, for example, Appino and Tsukada invoke a characteristic of kamishibai paper plays: kamishibai artists regularly omitted the final scenes of their stories in order to encourage repeat "customers." The technique is equally effective here: the refusal of narrative closure builds anticipation such that the kamishibaiya's quiet, private viewing of "Chapter 10" becomes a strikingly beautiful and profound moment, a fulfillment of the work's unspoken promise to its audience. Similarly, for English-speaking audiences, the benshi and 
kamishibaiya's Japanese narrations come to function much like silent film musical accompaniment (including Fain's within the work): they establish mood, guide emotional registrar, and offer hints about action more than they legibly narrate the action of the film or paper play. Indeed, it is frequently difficult to tell which sound effects are generated by the benshi and kamishibaiya, and which come from Fain's violin and prerecorded material; when Fain and Tsukada-as-kamishibaiya begin to move and make music in synchronization, their sonic, dancing bodies transcend simple boundaries between music, dance, and narrative. The creators of Club Diamond use intermediality to generate in audiences precisely the feeling of disorientation that Tsukada and her alter egos describe, enact, and embody. Yet the gaps, fissures, and sensations that result also reveal much more: the limits and possibilities of performance, the intimate connections between seemingly disparate media, and the aesthetic and narrative promise of medial transposition and borrowing.

\subsection{Conclusion}

Club Diamond, Roxy's broadcasts, Once to Every Woman, and The Unholy Three do not convey meanings and ideas as expected. As such, they remind us that mediation is not only about seamless and easy transmission of sensations and ideas across space, time, and bodies. Mediation can also prompt experimentation within a media product and/or a technical medium of display, as The Unholy Three does, or make tangible the unique possibilities and intermedial potential of multiple media, as in Roxy's Capitol Theater broadcasts. Mediation can push producers and perceivers to reimagine and differently experience medial boundaries, as in the Stratford's presentation of Once to Every Woman. Finally, mediation can purposefully and productively refuse smooth transmission in order to generate particular perceptual effects and bodily affects, as in Club Diamond. In each of the examples described above, and innumerable others, intermediality foregrounds various media's modal limits and mismatches, their expressive incompatibilities and shortcomings. At the same time, intermediality opens up new expressive fields and modes of representation, and stages unexpected perceptual possibilities. In his essay on media and theater, Peter Boenisch notes that intermediality is not just about transmission of messages, but also about activating audiences, inviting them into complex imagined worlds; it is as much a perceptual effect generated in 
performance as an inherent quality (Boenisch 2006: 114-115). Perhaps, then, intermediality is most potently generated in performances that challenge - and at times confound-the audience's expectations and understandings of media.

\section{Notes}

1. A variety of different intermedial "techniques" are on display in my examples. Some engage in medial transposition, moving and representing narratives and characters from one medium to another. Others borrow aesthetic conventions associated with one medium and deploy them in another. Still others recombine media in unexpected ways, or represent a series of media in another medium, one after the next. For more on these various "types" of intermediality, see, for example, Rajewsky (2005) and Chapple and Kattenbelt (2006).

2. Boenisch argues that intermedial performances can be profoundly unsettling for audiences, creating "effects of alienation and dys-referential unrealities" (2006: 115).

3. The 1925 version of The Unholy Three survives, as does the 1930 sound version discussed later in this section of the essay. Both are available commercially. See The Unholy Three (1925c). Directed by Tod Browning (2010; Warner Home Video), DVD and The Unholy Three (1930a). Directed by Jack Conway (2010; Warner Archives), DVD.

4. Among the numerous scholars who have made this claim is Rick Altman, who in his essay "Moving lips" argues that the illusion that film soundtracks are redundant and subservient to the image actually serves to constitute filmic unity. Film so prominently displays the speaking character precisely because seeing their moving lips helps to "transfer the origin of the words, as perceived by the spectator/auditor, from sound 'track' and loudspeaker to a character within the film's diegesis," disguising the film's construction and technologies (Altman 1980: 67, 69).

5. The speech bubble text in particular successfully remediates another popular early twentieth-century medium with which most filmgoers in 1925 would have been familiar: the comic strip.

6. Rothafel was among the earliest to so fully incorporate radio into his theater activities, but other exhibitors and film studios began experimenting with radio around the same time, and by 1924, many of Broadway's large film theaters, and those located in other major American cities, were also broadcasting their stage shows. See Douglas Gomery (2005: 16) for additional examples of silent film/radio experiments. 
7. For more on remediation, see Chiel Kattenbelt, "Intermediality: A redefinition of media and a resensibilization of perception", keynote lecture at Intermediality: Performance and Pedagogy conference at Sheffield University, 15 March 2007; Bolter and Grusin (1999: 56); Nikunen (2007: 113); Auslander (2003: 24).

8. This act of virtually recasting a media object in its original technical medium of display, or even immersing oneself in a narrative unbounded by a technical medium of display altogether involves the cross-modal cognitive capacities that Lars Elleström discusses in his "The modalities of media II" (2020: 68-69).

9. I discuss this film and its presentation at greater length in Simonson (2019).

10. For more on the relationship between silent film and opera, see GroverFriedlander (1999, 2002), Stern (2002), and Simonson (2013).

11. In addition to allowing audiences to hear a long-lost voice, this moment also enabled them to hear the specific song for which many were waiting. When the film was previewed at the Hotel Astor, a soprano was hired to sing "Ben Bolt" both before the screening began and when Aurora sings at her mother's bedside. The stunt was so well received that Universal launched a "song tie-up" campaign: they issued a special ad book containing piano-vocal sheet music and advised exhibitors to ask their local music stores to stock the sheet music, hold a weekly giveaway of one copy, and to feature in their window displays to help promote the film. If done right, Universal told exhibitors, audiences "will all want a copy of this songthey'll all be singing it - they'll be reading it. And when you show the picture, they'll be jamming your house during the entire run." See "Universal arranges song tie-up" (1920: 4446) and "Special Universal ad booklet for Once to Every Woman (1920: 18).

12. Benshi were considered crucial to film exhibition in Japan during the silent era, and often achieved levels of fame that surpassed that of film stars. For additional information about the practice, see, for example, Gerow (2010).

13. Tsukada's performance of these multiple, intertwined characters might usefully be analyzed through the multimodal performance framework that Andy Lavender proposes in this volume, based on a transposition of Elleström's media modalities (Lavender 2020).

14. The movie screen in Club Diamond functions similarly to (and might be considered) what Andrea Virginás labels a diegetic screen in her essay in this volume. As she notes, these screens are watched by diegetic characters (here, the benshi), directing our attention to Elleström's intracommunicational domain and heightening the act of perception that precedes interpretation (Virginás 2020: 152-159).

15. For more about kamishibai and kamishibai artists, see Orbaugh (2015) and McGowan (2015). 
16. To be clear, I am not suggesting that media require language to communicate; I agree with Elleström's identification of the problematic nature of such assumptions in his essay in this volume (Elleström 2020: 6). Rather, I am pointing out that it is striking that Club Diamond incorporates language as much to obscure as to transmit. Indeed, Club Diamond displays precisely media's ability to communicate despite language, as well as through language.

\section{REFERENCES}

Altman, Rick. 1980. Moving Lips: Cinema as Ventriloquism. Yale French Studies 60: 67-79.

Auslander, Philip. 2003. Liveness: Performance in a Mediatized Culture. New York: Routledge.

Boenisch, Peter M. 2006. Aesthetic Art to Aisthetic Act: Theatre, Media, Intermedial Performance. In Intermediality in Theatre and Performance, ed. Freda Chapple and Chiel Kattenbelt, 103-116. Amsterdam: Rodopi.

Bolter, Jay David, and Richard Grusin. 1999. Remediation: Understanding New Media. Cambridge, MA: MIT Press.

Chapple, Freda, and Chiel Kattenbelt, eds. 2006. Intermediality in Theatre and Performance. Amsterdam: Rodopi.

Chicago Theatre's Presentation Elaborate. 1921. Motion Picture News, January $1: 367$.

Chion, Michel. 1999 [1982]. The Voice in Cinema. Trans. Claudia Gorbman. New York: Columbia University Press.

Elleström, Lars. 2010. The Modalities of Media: A Model for Understanding Intermedial Relations. In Media Borders, Multimodality and Intermediality, ed. Lars Elleström, 11-48. Basingstoke: Palgrave Macmillan.

- 2020. The Modalities of Media II: An Expanded Model for Understanding Intermedial Relations. In Beyond Media Borders: Intermedial Relations among Multimodal Media, Volume 1, ed. Lars Elleström, 3-91. Basingstoke: Palgrave Macmillan.

Gerow, Aaron. 2010. Visions of Japanese Modernity: Articulations of Cinema, Nation, and Spectatorship, 1895-1925. Berkeley: University of California Press. Gomery, Douglas. 2005. The Coming of Sound: A History. New York: Routledge. Grover-Friedlander, Michal. 1999. The Phantom of the Opera: The Lost Voice of Opera in Silent Film. Cambridge Opera Journal 11 (2): 179-192.

. 2002. There Ain't No Sanity Claus. In Between Opera and Cinema, ed. Joe Jeongwon and Rose Theresa, 19-38. New York: Routledge.

Hollywood Highlights. 1925. Picture-Play Magazine, April: 114.

Inside stuff-Pictures. 1930. Variety, July 9: 49. 
Lanzius, Evelyn. 1923. Capitol Theater, New York, Broadcasts Sunday Evening Program Through WEAF. Radio Digest, June 2: 5.

Lavender, Andy. 2020. Multimodal Acting and Performing. In Beyond Media Borders: Intermedial Relations among Multimodal Media, Volume 1, ed. Lars Elleström, 113-140. Basingstoke: Palgrave Macmillan.

McGowan, Tara. 2015. Performing Kamishibai: An Emerging New Literacy for a Global Audience. New York: Routledge.

Melnick, Ross. 2012. American Showman: Sammel 'Roxy' Rothafel and the Birth of the Entertainment Industry. New York: Columbia University Press.

Moak, Bob. 1930. The first of Mr. Chaney. Talking Screen, May: 44-45, 80.

Nelson, Bradford. 1930. Lon Chaney Comes Back. Screenland, May: $32-33,116-117$.

Newell, Kate. 2020. Transferring Handmaids: Iconography, Adaptation, and Intermediality. In Beyond Media Borders: Intermedial Relations among Multimodal Media, Volume 2, ed. Lars Elleström, 33-57. Basingstoke: Palgrave Macmillan.

Nikunen, Kaarina. 2007. The Intermedial Practises of Fandom. Nordicom Review 28 (2): 111-128.

Orbaugh, Sharalyn. 2015. Propaganda Performed: Kamishibai in Japan's FifteenYear War. Leiden: Brill.

Rajewsky, Irina O. 2005. Intermediality, Intertextuality, and Remediation: A Literary Perspective on Intermediality. Intermédialités 6: 43-64.

Simonson, Mary. 2013. Body Knowledge: Performance, Intermediality, and Entertainment at the Turn of the Twentieth Century. New York: Oxford University Press.

- 2019. 'Adding to the Pictures': The American Film Prologue in the 1920s. American Music 37 (1): 1-28.

Special Universal ad Booklet for Once to Every Woman. 1920. Moving Picture Weekly, November 27: 18.

Stern, Lesley. 2002. The Tales of Hoffmann: An Instance of Operality. In Between Opera and Cinema, ed. Jeongwon Joe and Rose Theresa, 39-58. New York: Routledge.

The Shadow Stage: The Unholy Three. 1925. Photoplay, July.

The Unholy Three. 1925a. Exhibitor's Trade Review, 15 August: 45.

- 1925b. Motion Picture News, 15 August: 845.

- 1925c. Directed by Tod Browning (2010; Warner Home Video), DVD.

- 1930a. Directed by Jack Conway (2010; Warner Archives), DVD.

- 1930b. Film Daily, 6 July: 10.

The Unholy Three Advertisement. 1930. Film Daily, 19 July: 26. 
Universal Arranges Song Tie-Up. 1920. Motion Picture News, 11 December: 4446.

Virginás, Andrea. 2020. Electronic Screens in Film Diegesis: Modality Modes and Qualifying Aspects of a Formation Enhanced by the Post-Digital Era. In Beyond Media Borders: Intermedial Relations among Multimodal Media, Volume 1, ed. Lars Elleström, 141-173. Basingstoke: Palgrave Macmillan.

Open Access This chapter is licensed under the terms of the Creative Commons Attribution 4.0 International License (http://creativecommons.org/licenses/ by $/ 4.0 /$ ), which permits use, sharing, adaptation, distribution and reproduction in any medium or format, as long as you give appropriate credit to the original author(s) and the source, provide a link to the Creative Commons licence and indicate if changes were made.

The images or other third party material in this chapter are included in the chapter's Creative Commons licence, unless indicated otherwise in a credit line to the material. If material is not included in the chapter's Creative Commons licence and your intended use is not permitted by statutory regulation or exceeds the permitted use, you will need to obtain permission directly from the copyright holder.

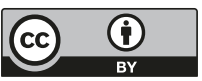

